\title{
The Prototype of Non-thermal Plasma After treatment System for Simultaneous Reduction of Nitrogen Oxide Emission in Flue Gas
}

\author{
Dararat Laohalertdecha ${ }^{1}$, Kampanart Theinnoi ${ }^{1,2, ~ *}$ and Sak Sittichompoo ${ }^{3}$ \\ ${ }^{1}$ College of Industrial Technology, King Mongkut's University of Technology North Bangkok, 1518 Pracharat 1 Road, \\ Wongsawang, Bangsue, Bangkok 10800, Thailand. \\ ${ }^{2}$ Research Centre for Combustion Technology and Alternative Energy (CTAE), Science and Technology Research Institute, \\ King Mongkut's University of Technology North Bangkok, Bangkok 10800, Thailand. \\ ${ }^{3}$ Mechanical Engineering, School of Engineering, University of Birmingham, Edgbaston, Birmingham B15 2TT, United Kingdom.
}

\begin{abstract}
Nowadays, global warming is the main environmental problems all over the world. The air pollutants mainly from the burning of fossil fuels and coal in power plants, transportation, and automobiles. There are release major point emission of the atmosphere. The nitrogen oxides are the most relevant for air pollution that contribute to the formation of photochemical smog and acid rain. Numerous methods have been studied to eliminate the nitrogen oxides such as the use low-nitrogen fuels technology, the selective catalytic reduction (SCR), wet scrubbing. The aim of this research is investigated non-thermal plasma (NTP) techniques offer an innovation to eliminate both nitrogen oxide (NOx) and soot emissions from combustion. This study is used to selectively transfer input electrical energy to electrons without expending this in heating the entire gas flow which creates free radicals in the flue gases. The simulated flue gas from combustion process is applied to the system. The results showed that the prototype of nonthermal plasma system is shown the highly efficient of NOx removal was achieved. However, the optimised of NTP operating conditions are required to enhance the NOx reduction activities.
\end{abstract}

Keyword. Non-Thermal plasma (NTP), Nitrogen Oxide, Flue Gas, Emissions

\section{Introduction}

Nitrogen oxides are toxic emissions produced from diesel combustion and consist of nitric oxide (NO) and nitrogen dioxide $\left(\mathrm{NO}_{2}\right)$. The nitrogen oxides from combustions are mainly air pollution generated by fuel combustion from stationary and mobile sources in the atmosphere. $\mathrm{NO}_{\mathrm{x}}$ emission can cause a series of health and problems such as eye and throat irritation and headache and environment issues such as toxic chemical smog and acid rain [1]. The post combustion technologies, selective catalytic reduction (SCR) has become dominant in controlling NOx emission from industries i.e., utility boilers and industrial furnace stacks [2-3]. However, there are many improvements aimed to reducing the SCR systems cost have been achieved, due to the space requirements and operating cost are still high cost [4]. The generation of ammonia emissions and the fouling of equipment with ammonium sulphate.

Given the health of diesel emission, power plant and combustion, there is an explicit to regard novel technologies to remove the tailpipe emissions. The highly traffic jam in urban areas is a big main problem of Nitrogen Oxide [5-6]. Thus, Non-thermal plasma (NTP) is an alternative chance for after treatment application to control emission [7]. Plasma is term that used to identify to fourth state of matter apart from the three well known states [8]. The three states are the state of matter that temperature increases which molecules are enormous energy and break down form solid, liquid, gas into plasma. Stage of plasma is more likely gaseous which its atoms and other free moving charge disassociated and collision between charges is observed. Commonly, plasma is involved electric and very conductivity greater than metal. There are two type of plasma that are thermal plasma and non-thermal plasma. Thermal plasma is normally affected very high power and reaction temperature from $10,000 \mathrm{~K}$ to $100,000 \mathrm{~K}$. NTP offers lower implementation cost for system as it has better species selective characteristic with higher energy conversion efficiency. A novel power supply is used, which enables high voltage and high frequency operation for optimized electrical power input into the plasma. NTP can be operated at room temperature and atmospheric pressure [9].

Among the emerging technologies for postcombustion treatment, non-thermal plasma (NTP) is an advance oxidation method. During the NTP process, many active radicals, such as $\mathrm{O}, \mathrm{OH}$ and $\mathrm{O}_{3}$ are generated. These oxidize gaseous pollutants such as volatile organic compound (VOC), NOx and particulate matter (PM) at room temperature and atmosphere pressure [10]. NTP

* Corresponding author: kampanart.t@ cit.kmtunb.ac.th 
holds the advantages high oxidation efficiency, low floor area, no chemical addition, low initial cost, low temperature and at atmospheric pressure, and energy consumption [11]

Non-thermal plasma (NTP) as a useful method for NOx removal has been investigated in many years. It is almost primary pollution and has a good application prospect. This method is used to selectively transfer input electrical energy to the electrons without heating temperature the whole gas flow which generates free radicals through collisions and supports the preferred chemical changes in the exhaust gases. The created active species react with the pollutant molecules and followed by decomposition of pollutants.

This work is focused on the design of prototype of nonthermal plasma reactor for nitrogen oxide reduction in flue gas. The aim of the study is to obtain a high influence of applied voltage and electrode configuration parameters on the optical and electrical performance on the plasma reactor. In addition, the electrode configuration of plasma reactors is also investigated.

\section{Experimental Apparatus and Procedure}

The prototype NTP reactor was designed and developed in laboratory scale. The experiment schematic diagrams as shown in Fig. 1 is composed of NTP reactor, a high voltage power supply, a high voltage probe, a digital oscilloscope, and a flue gas analyser. The simulated flue gas was feed under atmospheric pressure to nonthermal plasma (NTP) reactor which gas flow rate was controlled by a digital gas mass flow controller. Then the supernatant was analysed through flue gas analyser.

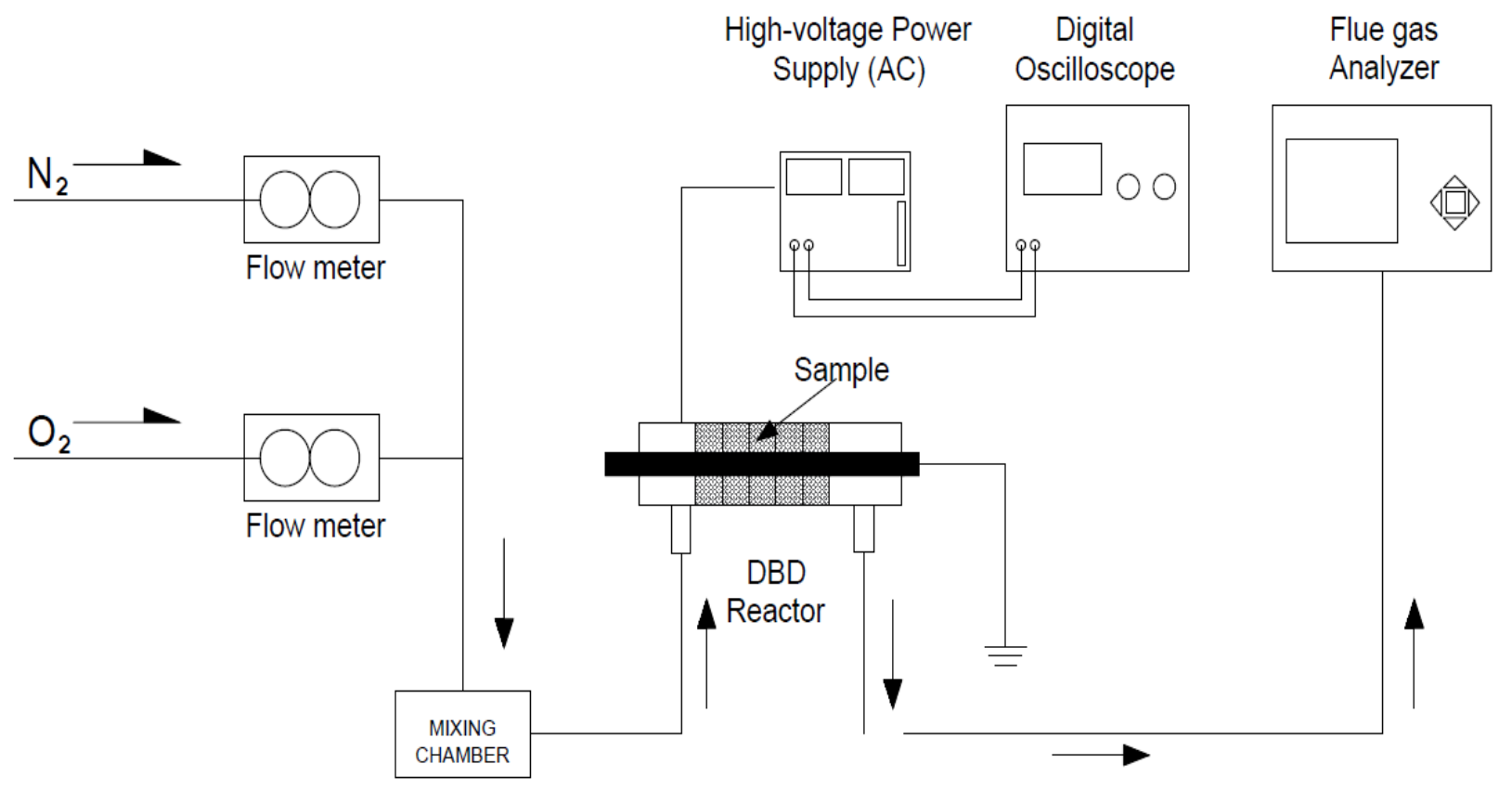

Fig. 1. Schematic diagram of the experimental setup for the non-thermal plasma Non-thermal plasma (NTP).

\subsection{Experiment system and Conditions}

A commercial grade nitrogen gas and oxygen-based nitrogen with a purity of $99.5 \%$ and nitrogen oxide gas in nitrogen with $500 \mathrm{ppm}$ concentration were use as simulated flue gas from combustion. The total simulated gas flow rate was controlled about $10 \mathrm{~L} / \mathrm{min}$ via a mass flow controller to keep resident time constant. The simulated flue gas was passed in to NTP reactor. The flue gas was discharged by a high voltage (HV) power supply and plasma was generated at the same time. It flowed out of the reactor and according to the flue gas analyser's measurement. Then the plasma power source is turned on to generate NTP. The output power of the power source was adjusted by input voltage and input current. And the concentrations of the reactor outlet gas at different powers were monitored. The input voltage of the plasma power source was controlled by the frequency adjustment knob of the plasma power source.

\subsection{Non-thermal plasma (NTP) reactor}

The non-thermal plasma reactor was designed in length $200 \mathrm{~mm}$ and width $100 \mathrm{~mm}$ as shown in Fig.2 (a) and (b). It consists of 40,20,10,5 copper sheets of electrodes that was connected to HV electrode. The copper metal plate dimensions are the length $(200 \mathrm{~mm})$ and the width (100 $\mathrm{mm})$ and the thickness $(1 \mathrm{~mm})$. The downstream region for measurement of the voltage variation and isolate form the ground. The dynamic variation of the metal-plate voltage was measured via oscilloscope and HV probe. The metal-plate voltage was monitored under ionization wave reaching to the metal plate. The high voltage input 
of the metal plate was kept constant at the range of $10 \mathrm{kV}$, which implies the change of the space potential in the plasma jet under z-axis positions and discharge voltage conditions [12]. The effective discharge length is approximately $200 \mathrm{~mm}$. The discharge gap in this study is 20, 40 and $60 \mathrm{~mm}$.

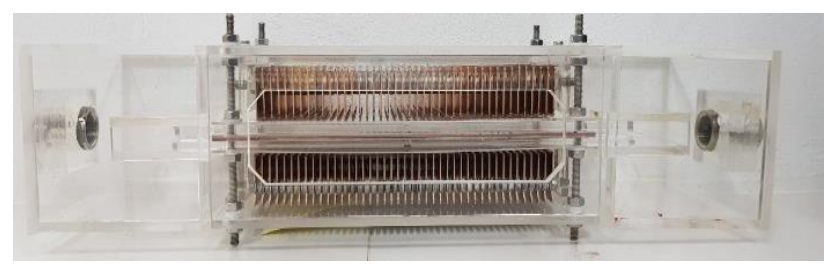

(a)

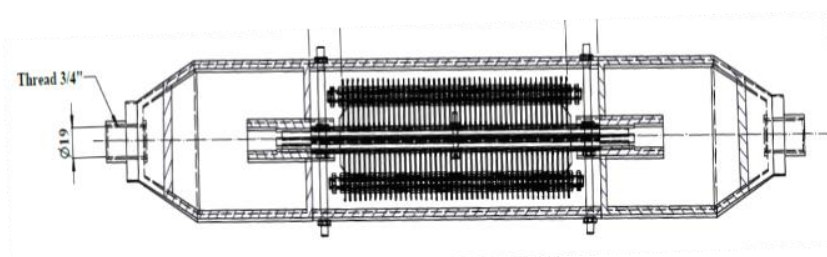

(b)

Fig 2. (a) The non-thermal plasma reactor, (b) the non-thermal plasma drawing.

\subsection{Electrodes}

Electrode is an important part of the conductivity of a reaction. An electrode in an electrochemical cell is referred to as either an anode or a cathode [13-14]. It has both an anode and a cathode side. The copper material has been selected as electrodes due to the properties of copper has the low electrical resistance $\left(1.93 \times 10^{-9} \Omega \mathrm{cm}\right)$ that has the high current flow [15-16].

\subsection{Electric measurements}

The important key parameters to evaluate a pollution control system is the energy consumption. It was determined form simultaneous measurements of the discharge current and applied voltage. The DC Voltage applied to the electrode is measured by using an $\mathrm{HV}$ probe (Testec TT-HVP15 HF 500MHz $10 \mathrm{kV}$ ). The electrical wave form was monitored via a fast digital oscilloscope (Keysight Technologies DSOX1204).

\subsection{Electric measurements}

All experiments were conducted under ambient temperature and pressure. Space velocity is the ratio between gas flow rate through reactor and effective volume of the reactor as shown in Eq.1

$$
\mathrm{SV}=\frac{\text { Qgas }}{\text { Veff }} \quad\left(\mathrm{h}^{-1}\right)
$$

Where $\mathrm{Qgas}_{\mathrm{g}}\left(\mathrm{m}^{3} / \mathrm{h}\right)$ is the exhaust gas volumetric flow rate and $V_{\text {eff }}\left(\mathrm{m}^{3}\right)$ is the reactor Volume. Increasing the space velocity results in high gas flow rate pass through the reactor lead to less time for reaction. The experiment conditions with NTP were designed to obtain results which affected by position electrode, reactor discharge gap and reactor high voltage input power as shown in Table1.

Table 1. Electrode configuration parameters investigated in this work.

\begin{tabular}{ccc}
\hline Item Value No. & $\begin{array}{c}\text { Number of } \\
\text { copper }\end{array}$ & $\begin{array}{c}\text { Discharge gap } \\
(\mathbf{m m})\end{array}$ \\
\hline 1 & 40 & 20 \\
2 & 40 & 40 \\
\hline 3 & 40 & 60 \\
4 & 20 & 20 \\
\hline 5 & 20 & 40 \\
6 & 20 & 60 \\
\hline 7 & 10 & 20 \\
8 & 10 & 40 \\
\hline 9 & 10 & 60 \\
10 & 5 & 20 \\
\hline 11 & 5 & 40 \\
12 & 5 & 60 \\
\hline
\end{tabular}

\subsection{Flue gas concentration measurements}

Gas analysis model MEXA-584L from Horiba includes measurement of carbon dioxide, carbon monoxide and unburned hydrocarbons (NIDR-non-dispersive infrared), oxygen (magneto pneumatic sensor), and $\mathrm{NO}_{\mathrm{x}}$ (CLDchemi-luminescence detection). In this work, the flue gas in each operating condition is measured and reported.

\section{Result and discussion}

The aim of this study to optimize the electrode position, which are the number of copper electrodes and discharge gap between electrode, to finding the best $\mathrm{NO}_{\mathrm{x}}$ reduction efficiency in NTP reactor. The power loss in system is also investigated. The reactor sizing to estimate the length and diameter of the reactor according to the empirical formula.

\subsection{The effect of electrode configurations on the power input}

This experiment was optimized the effective range of NTP reactor. The NTP power input are dependent on many parameters inclusive of the number of electrode copper sheets ( 5 sheets to 40 sheets), electrodes gap (40 $\mathrm{mm}$ to $5 \mathrm{~mm}$ ) and fixed discharge gap at $20 \mathrm{~mm}$. All electrode configurations are shown in Fig. 3

The input voltage is generally related to the ionization degree to reaction with feed gas in NTP reactor. In additions, the electrical energy, discharge gap and number of coppers of the plasma reactor are all parameters that affect the number of energetic electrons [12]. The increasing input plasma power may effectively 


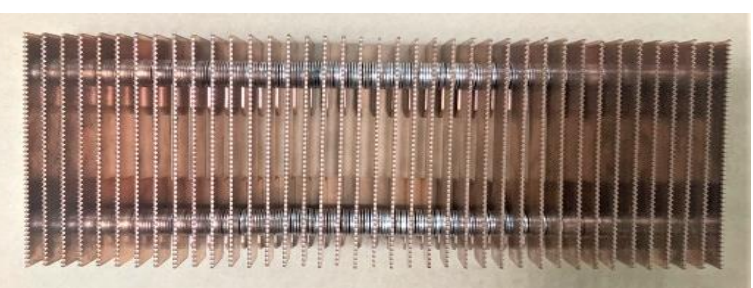

(a)

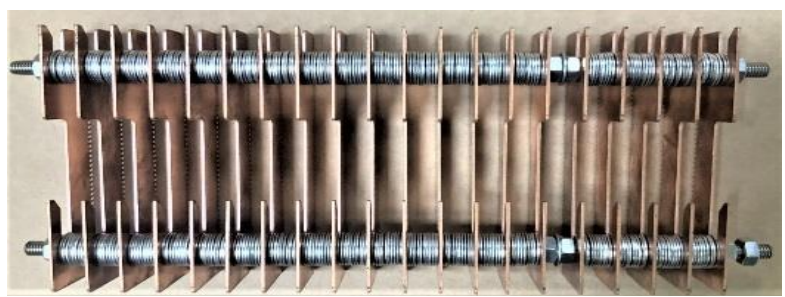

(b)

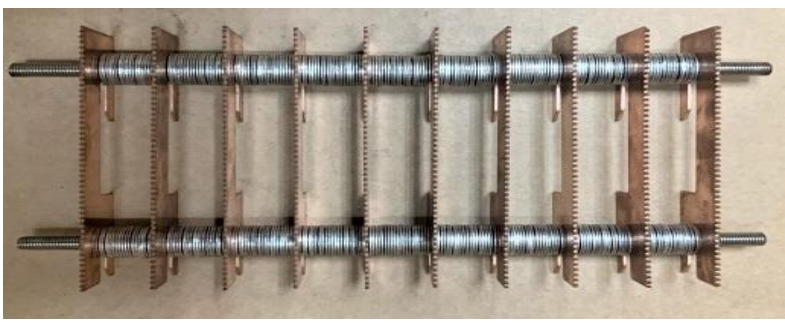

(c)

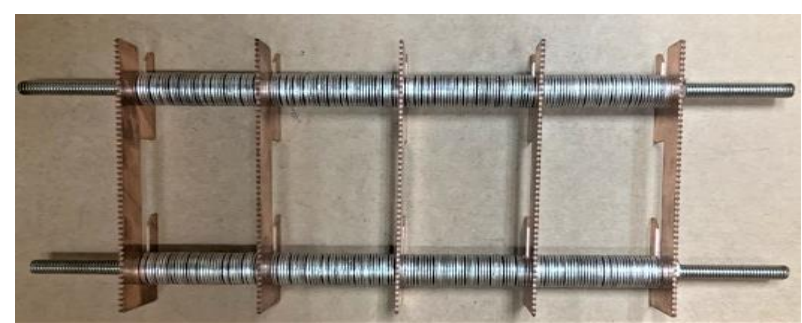

(d)

Fig. 3. Schematic diagram of the amount of copper (a) 40 sheets (electrodes gap $5 \mathrm{~mm}$ ) (b) 20 sheets (electrodes gap $10 \mathrm{~mm}$ ) (c) 10 sheets (electrodes gap $20 \mathrm{~mm}$ ) and (d) 5 sheets (electrodes gap $40 \mathrm{~mm}$ )

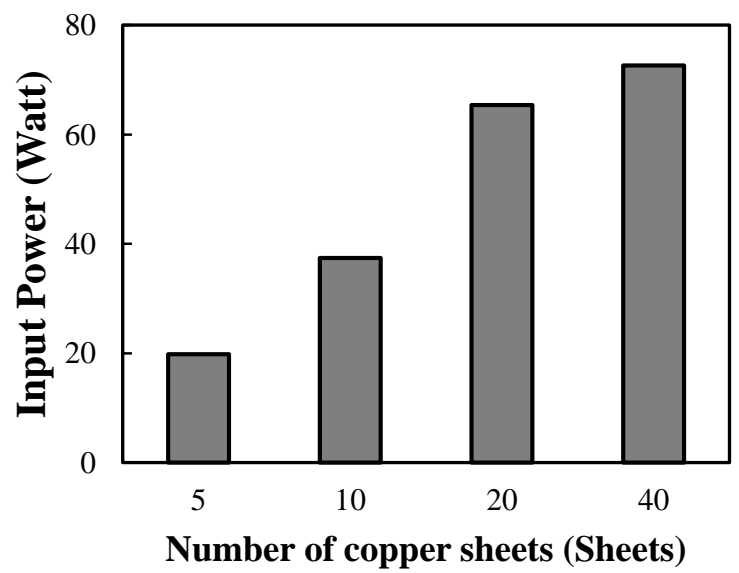

Fig. 4. Effect of electrode to apply input power

enhance the electric field, electron density under a constant excitation frequency. This also provides high energy to electrons consequently which can be enhanced the pollution removal efficiency [17]. The high amount of cooper sheets is increasing power input (high power consumption) under the same reaction zone $\left(200 \mathrm{~cm}^{2}\right)$ as seen in Fig.4. To increasing the resistance with higher copper sheets. In addition, the higher number of copper sheets are requiring high level of energy source to generate plasma beam. The applied voltage supply is required to overcome the electrical impedance with high resistant (high amount of copper sheets). The plasma per reaction area has not work full efficiency, thus optimization of number of sheets for operating conditions was found to be crucial in enhancing plasma beam efficiency and applications. The 20 copper sheets with 10 $\mathrm{cm}$ electrode gap were selected in this experiment due to the power output is suitable to for $\mathrm{NO}_{\mathrm{x}}$ reduction application. The input power for 40 copper sheets with 5 $\mathrm{cm}$ electrode gap has slightly higher than 20 copper sheets due to the small electrode heat losses.

\subsection{The effect of discharge gap on input power}

The influence of discharge gap on plasma beam performance has been studied to the optimum energy utilization in normal thermal plasma beam generation. The electrode configurations are following; discharge gap is 20,40 and $60 \mathrm{~mm}$ with fixed copper 40 sheets.

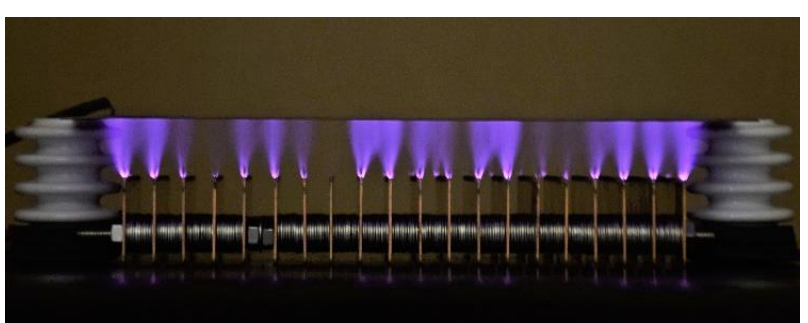

(a)

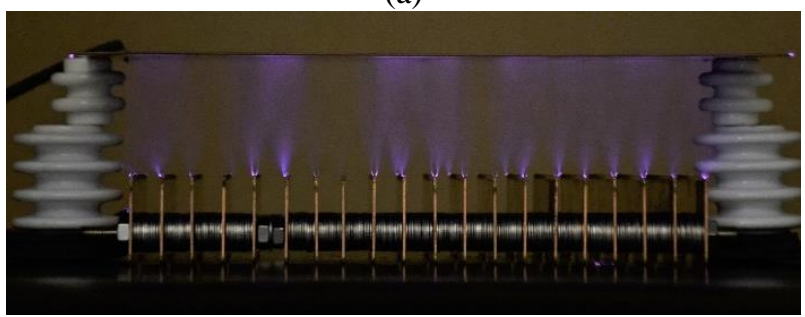

(b)

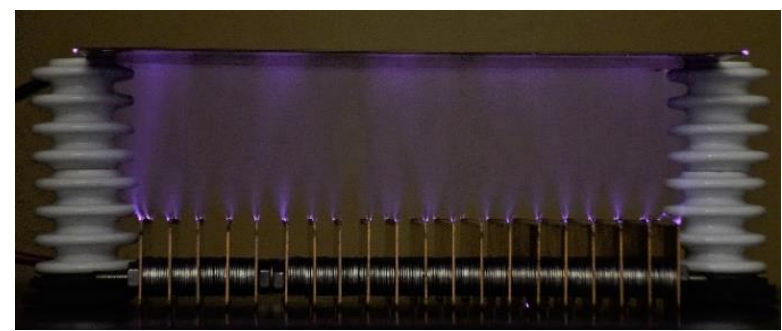

(c)

Fig. 5. Side view of plasma beam layer under different discharge gap (a) discharge gap $20 \mathrm{~mm}$, (b) discharge gap $40 \mathrm{~mm}$ and (c) discharge gap $60 \mathrm{~mm}$

Fig.5 shows the various discharge gap on plasma beam and the input power under atmospheric conditions (without simulated gas feed). The plasma beam density was dependent on the discharge gap due to its different power input and followed the general trend: discharge gap 
$20 \mathrm{~mm}>$ discharge gap $40 \mathrm{~mm}>$ discharge gap $60 \mathrm{~mm}$ as shown in Figure 5. The plasma beam in atmospheric condition show phenomena similar with uniform electric field under atmospheric condition as seen in Fig.5. The high electric field density occurring under the voltage lower than break down voltage. In additions, the electric field density was reduced under the increasing discharge gap because the ionization reaction between two electrodes is decreased. During begin, the discharge inception of semiconductor to produce external plasma beam is controlled by the specific conductivity of electrode. Thus, the capacity per electrode area unit, also called effective capacity, are very important for plasma density. Therefore, the voltage drop across the high gas gap leads to high electrical breakdown [18].

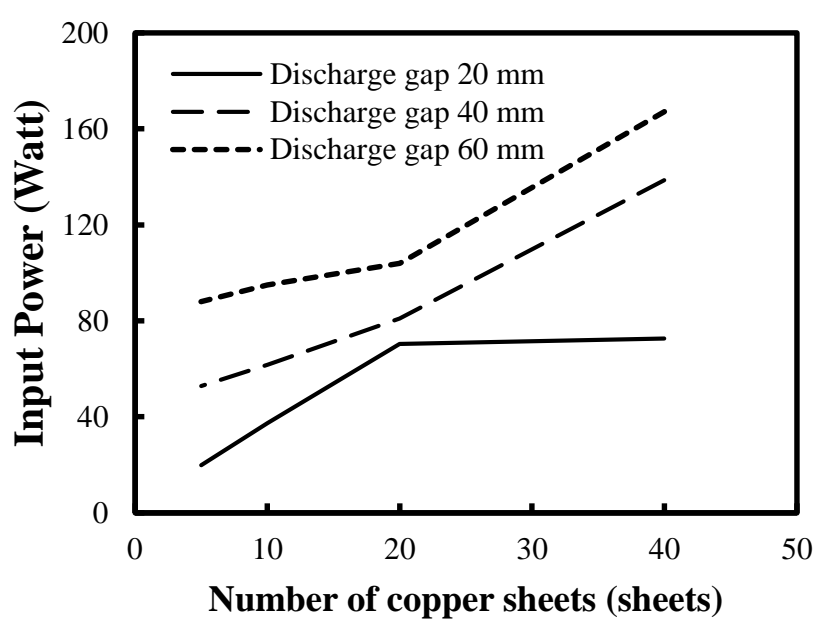

Fig. 6. Effect discharge gap of electrode to apply input power

The discharge gap is an important factor affecting electrical power input. The electron field behavior generally moves from a higher potential pole to a lower potential pole. The free electron can be move easily to lower potential pole under small discharge gap thus, the maximum electric field with small power input as shown in Fig.6. The highest power is 167.2 watts at 40 electrodes, discharge gap $60 \mathrm{~mm}$ and the minimum power is 19.8 watts at 5 electrodes, discharge gap $20 \mathrm{~mm}$. The results can analyze that number of electrodes and the discharge affect to power consumption. In additions, the power generated is less than the other discharge gap in all cases. The discharge gap can have a significant influence on the number of micro-discharges. Therefore, the discharge gap can generate significant influence on the optical and electrical characteristics of the plasma reactor [19-20].

Furthermore, the number of electrodes and discharge is a very important factor to power consumption. The high number of electrodes will affect to higher power input. The input power is related to the electrode material resistance. Therefore, the high number of electrodes with high electric resistance are required the higher power to overcome electrodes resistant.

\subsection{The influence of $\mathrm{NO}_{x}, \mathrm{NO}, \mathrm{NO}_{2}$ removal activity over NTP reactor}

This section presents the prototype of NTP reactor activities on $\mathrm{NO}_{x}, \mathrm{NO}, \mathrm{NO}_{2}$ removal efficiency. The prototype configuration was selected as following; discharge gap $60 \mathrm{~mm}, 40$ sheet of copper electrode sheets and approximate 168 watt of input-power that is the maximum condition for NTP reactor in this study. The simulated flue gas was feeding rate at $10 \mathrm{~L} / \mathrm{min}$. The result found that NTP reactor can be $\mathrm{NO}_{\mathrm{x}}$ removal of approximately $78 \%$ and consist of nitric oxide (NO) removal $99 \%$ and nitrogen dioxide $\left(\mathrm{NO}_{2}\right)$ production $93 \%$ as shown in Fig.7.

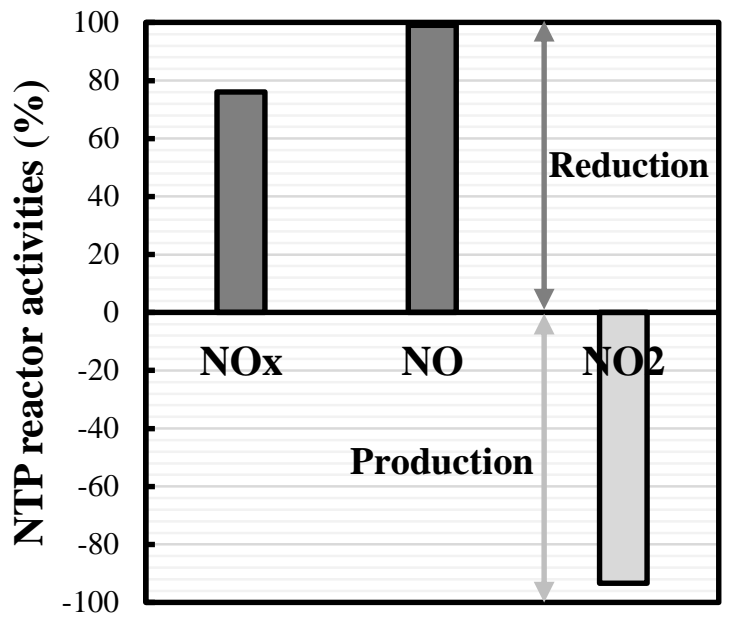

Fig. 7. $\mathrm{NO}_{\mathrm{x}} \mathrm{NO}, \mathrm{NO}_{2}$ reduction activities over NTP reactor

Reactor with NTP has increase the electric filed strength and electron density and provides more energy to electrons consequently leads to high NOx removal efficiency, supports high removal efficiency in this reactor [21]. In addition, the plasma reaction can reduce $\mathrm{NO}$ as the main component of NOx pollution, which then transforms to $\mathrm{NO}_{2}>99 \%$ that are active in a discharge zone.

\section{Conclusion}

The preliminary study of prototype non-thermal plasma reactor design for NOx reduction presents a solution to the current challenge of air pollution over the combustion. The influencing working parameters such as the applied voltage, discharge length, interval between adjacent outer electrodes and electrode width were all considered to obtain a further and deeper understanding of the discharge characteristics of the multi-electrode plasma reactor. The efficient length and fringe effect were found to be the two significant reasons for the change of the optical and electrical performance. In additions, the prototype of NTP reactor could significantly enhanced $78 \%$ of NOx reduction activity. This benefit could be utilized with the nonthermal plasma technology to purpose continuous NOx reduction. Moreover, contribute to an improved post 
treatment (e.g., SCR, Lean-NOx trap) aiming to achieve future emissions regulations that include control of NOx.

\section{References}

1. G. Xiao, W. Xu, Non-Thermal plasmas for VOCs abatement, Plasma Chemistry and Plasma Processing, 34, (2014): 1033-1065

2. F. Gholami, M. Tomas, Technologies for the nitrogen oxides reduction from flue gas: A review, Science of The Total Environment, 714, (2020): 136-712

3. Meunier, F., Breen, J., Zuzaniuk, V., Olsson, M., Ross, J., Mechanistic Aspects of the Selective Reduction of NO by Propene over Alumina and silver, Journal of Catalysis, 187, (1999): 493505

4. F. Gholami, Technologies for the nitrogen oxides reduction from flue gas: A review, Science of the Total Environment, Science of The Total Environment, 714, (2020): 136

5. K.H. KIM.S.-B. Lee, S.H. Woo, NOx Profile Around a Signalized Intersection of Busy Roadway, Atmospheric Environment, 97, (2014): 141-154

6. T. Rungratanaubon, Vertical Variation of Nitrogen Oxide (NOx) Concentration Using a Backward Air Mass Trajectories Model in an Urban Area of Bangkok, Thailand, KMUTNB International Journal of Applied Science and Technology, 11, (2018): 73-81

7. L. Zhang, X.Zhu, Effects of water pressure on plasma sparker's acoustic characteristics, International Journal of Plasma Environmental Science and Technology, 11, (2017): 60-63

8. M. Gallagher, Patial Oxidation and Autothermal Reforming of Heavy Hydrocabon Fuels with Non-Equilibrium Gliding Arc Plasma for Fuel Cell Applications, iDEA: Drexel Libraries ERepository and Archives, (2010): 1-5

9. N. Takamura, D. Wang, D. Seki, T. Namihira, K Yano, H Saitoh, H Akiyama, Protein Transduction into Eukaryotic Cells using Nonthermal Plasma, International Journal of Plasma Environmental Science and Technology, 6, (2012): 59-62

10. S. Li, Y. Huang, F. Wang, J. Liu, F. Feng, X. Shen, Fundamentals and environmental applications of non-thermal plasma: multipollutants emission control from coal-fired flue gas, Plasma Chem Plasma Process, 34, (2014): 579-603

11. S. Ma, Y. Zhao, J. Yang, S. Zhang, C. Zhang, Research progress of pollutants removal from coal-fired flue gas using non- thermal plasma, Renewable and Sustainable Energy Reviews, 67, (2017): 791-810

12. Y. Setsuhara, G. Uchida, K. Kawabata, A. Nakajima, K. Takenaka, Analysis of dynamic discharge characteristics of plasma jet based on voltage and current measurements using a metal plate, IEEE Transactions on Plasma Science, 43, (2015): 3821-3826

13. W. William, History of the Inductive Sciences: From the Earliest to the Present Times, Cambridge University Press, (2010)

14. M. Moscosa-Santillan, Design of a DBD wirecylinder reactor for $\mathrm{NOx}$ emission control: experimental and modelling approach, Journal of Cleaner Production, 16, (2008): 198-207

15. F. Pawlek, D. Rogalla, The electrical resistivity of silver, copper, aluminium, and zinc as a function of purity in the range $4-298{ }^{\circ} \mathrm{K}$, Cryogenics, 6, (2016): 14-20

16. L. Haiyun, L. Zhuo, W. Xinxin, Homogeneous dielectric barrier discharge in nitrogen at atmospheric pressure, Journal of Physics D Applied Physics, 43, (2010): 15

17. M. Laroussi, I. Alexeff, J. Richardson, Effects of nonequilibrium atmospheric pressure plasmas on the heterotrophic pathways of bacteria and on their cell morphology, Applied Physics Letters, 81, (2002): 772-774

18. H. Nguyen, K. Kyo-Seon, Combination of plasmas and catalytic reactions for $\mathrm{CO}_{2}$ reforming of $\mathrm{CH}_{4}$ by dielectric barrier discharge process, Catalysis Today, 256, (2015): 88-95

19. L.M. Portsel, Y.A. Astrov, I. Reimann, E. Ammelt, H.G. Purwins, High speed conversion of infrared images with a planar gas discharge system, Journal of Applied Physics, 85, 3960 (1999)

20. L.S. Wei, D.K. Yuan, G.P. Dong, H.U. Zhao-Ji, Z.H. Tan, Experimental study on ozone generation using high-frequency coaxialcylinders DBD in oxygen, CNKI: Nanchang University, 37, (2013): 2209-2211

21. R. Dawson, J. Little, Characterization of nanosecond pulse driven dielectric barrier discharge plasma actuators for aerodynamic flow control, Journal of Applied Physics, 113, (2013): 605 